\title{
Chlorophyll Biosynthetic Capacity and Xanthophyll Cycle of a White-Green Variegated Ficus microcarpa Cv. Milky Stripe
}

\author{
Shih $\mathrm{TH}^{1}$, Lee TC ${ }^{1}$, Huang MY2* and Yang CM${ }^{1 *}$ \\ ${ }^{1}$ Biodiversity Research Center, Academia Sinica, Taiwan \\ 2Departments of Horticulture and Biotechnology, Chinese Culture University, Taiwan
}

*Corresponding author: Yang CM, Huang MY, Biodiversity Research Center, Academia Sinica, Department of Horticulture and Biotechnology, Taiwan, E-mail: cmyang@gate.sinica.edu.tw, hmy6@ulive.pccu.edu.tw

\section{Abstract}

The white sector in the variegated leaves are studied by the variegated mutant lines, but the photosynthetic properties in the leaves of natural plant were less been examined. In present study, we analyzed the chlorophyll biosynthetic capacity and xanthophyll cycle components in the green and white sectors of variegated leaves of milky stripe fig (Ficus microcarpa cv. milky stripe). The white sector had approximately $2.2 \%$ as much chlorophyll and $9.5 \%$ as much carotenoid as does the green sector, but the ratio of carotenoid to chlorophyll in the white sector was 5.3- fold higher than that in the green sector. HPLC analysis demonstrated that, excepting neoxanthin, all other identified carotenoids were presented in large quantities in the green sector than in the white sector. The rate of degradation of protoporphyrin IX (PPIX), magnesium protoporphyrin IX (MGPP), and protochlorophyllide (Pchlide) in the white sector was higher than that in the green sector. $\Delta$-Aminolevulinic acid (ALA)-supplementation test indicates that the chlorophyll biosynthesis between ALA and Pchlide was partially impaired in the white sector, but is remarkably impaired in the steps after Pchlide. This study revealed the deficient process of photosynthesis and the importance of xanthophyll cycle in the white sector of natural leaves.

Keywords: Antheraxanthin; Chlorophyll; Magnesium protoporphyrin IX; Neoxanthin; Protochlorophyllide; Protoporphyrin IX; Violaxanthin; Xanthophyll cycle; Zeaxanthin

Abbreviations: ALA: $\delta$-Aminolevulinic Acid; HPLC: High Performance Liquid Chromatography; LHCP: LightHarvesting Chlorophyll Protein complex; MGPP: Magnesium Protoporphyrin IX Pchlide Protochlorophyllide; PSI: Photosystem; PSII: Photosystem II; PPIX: Protoporphyrin IX

\section{Introduction}

Variegation is found in leaves, stems, and flowers of many plants. Each leaf of a variegated plant, even from the same branch, displays its own specific variegational pattern. Several mechanisms are proposed to explain the polymorphism of pattern formation in variegated leaves $[1,2]$. The white, yellow, and yellow-green sectors of 


\section{Open Access Journal of Agricultural Research}

variegated plants differ in their plastid content. They contain either plastids containing only carotene or xanthophyll, or leucoplasts---plastids in various stages of degeneration leading to their complete disappearance. Their main ultrastructural characteristics are structural deformation of the plastids, single thylakoid lamellae, irregular grana and aberrant fretwork, aggregation of plastoglobuli, and absence of starch [3-9]. Most of the above plastid defects were also reported in chlorophylldeficient and virescent mutants [10-12]. Besides the above ultrastructural defects, the main biochemical defects of the mutant plants are the lack of certain polypeptides and enzymes needed for the buildup of PSI, PSII, and LHCP $[1,12,13]$. The analysis of variegated mutant immutans (im) in Arabidopsis (Arabidopsis thaliana) shows that the lack of plastid terminal oxidase (PTOX), which is responsible for plastid biosynthesis, resulted in the white sector of leaves $[2,14,15]$. Study of another white/yellow variegated mutant var2 in Arabidopsis also indicates that the variegated leaf is also induced by the deficient of thylakoid protein FtsH [16]. These researches reveal the role of chlorophyll synthesisrelated molecules in mutant lines, but the biosynthesis and the photopigments in natural white sector have yet been characterized.

The xanthophyll cycle, a mechanism of thermal dissipation of excess energy directly within the photochemical apparatus, is ubiquitous in the thylakoid membranes of all higher plants, ferns, mosses, and several algae. The dissipation mechanism consists of photoconversion of three oxygenated carotenoids in a cyclic reaction involving a light-dependent deepoxidation reaction from the diepoxide violaxanthin via the monoepoxide antheraxanthin to the epoxide-free form zeaxanthin, and an epoxidation reaction in the reverse direction [17-20]. The photoconversion of violaxanthin to antheraxanthin and zeaxanthin begins when the plants are exposed to high light stress [21,22], and this conversional process is thought to be a protective mechanism for plant from suffering photo-oxidative damage [23-25]. The photoprotective role of xanthophyll is found in the variegated mutant im of Arabidopsis, showing that the $\mathrm{im}$ seedling is unable to biosynthesize carotenoids [15]. Although these study in Arabidopsis mutants indicate the function of xanthophyll, the composition of photopigments in the natural variegated plant are still need to be analyzed to examine the natural properties in the variegated leaf.

Milky stripe fig (Ficus microcarpa) is a variegated plant in which the leaf is commonly shows green sector in central and surrounded by white margin (Figure 1A, B). The patterns of variegation typically follow the main veins of the leaf. The white sector of this variegated plant looks like the leaf of an etiolated plant. The aim of this work is to examine the capacity of chlorophyll biosynthesis and of xanthophyll cycle in the white and green sectors of variegated leaf of milky stripe Fig. Our data showed that the biosynthesis of chlorophyll in nature white sector is deficient in the process between protochlorophyllide and chlorophyll. We also found an increasing ratio of carotenoid to chlorophyll in the white sector, suggesting a protective mechanism is induced in the white sector.

\section{Materials and Methods}

\section{Plant Material}

Milky stripe fig (Ficus microcarpa cv. milky stripe) plants about $50 \mathrm{~cm}$ tall were purchased from a local nursery farm and grown in a greenhouse with natural light for 1 month. Only mature variegated leaves were used in this research.

\section{Assay Chlorophyll and Carotenoids}

Chlorophyll and carotenoid concentration were determined according to an integrated method following extraction with $80 \%(\mathrm{v} / \mathrm{v})$ acetone [26]. The absorbance of the extracts was determined with a Hitachi U2000 UVvisible spectrophotometer.

\section{Assay Porphyrin}

Half-centimeter disks were punched from the green and white sectors of milky stripe fig leaf. The leaf disks were incubated in a petri dish containing $5 \mathrm{ml}$ of $5 \mathrm{mM}$ sucrose with or without $2.5 \mathrm{mM} \delta$-aminolevulinic acid (ALA, a precursor for chlorophyll synthesis). To prevent photochemical conversion of protochlorophyllide (Pchlide) to chlorophyll, the following procedures were performed in a darkroom equipped with a dim green safelight. After 2, 4, 6 and 20-h incubation in the dark, the leaf disks were weighed, frozen with liquid-nitrogen, ground, and extracted in $80 \%$ ammoniacal acetone (acetone/ammonia: 8/2, v/v), and the extract was clarified by centrifuging at $2500 \mathrm{~g}$ for $5 \mathrm{~min}$. The concentrations of chlorophyll biosynthetic intermediates protoporphyrin IX (PPIX), magnesium protoporphyrin IX (MGPP), and Pchlide were determined using the integrated spectrophotometric method [26]. To minimize the interference of chlorophyll with the determination of porphyrin intermediates, the ammoniacal acetone extract was treated with hexane to remove the majority of 


\section{Open Access Journal of Agricultural Research}

chlorophylls

\section{HPLC carotenoids}

Pigments were extracted from leaves according to the method of Braumann and Grimme [27]. HPLC was conducted on a Vercopak inertsil 10 ODS $25 \times 4.6 \mathrm{~mm} \mathrm{C18}$ reverse phase column $(10 \mu \mathrm{m}$ particle size $)$. Two mobile phases applied as described previously [28,29] were pumped by a Waters M510 high pressure pump at a flow of $2.5 \mathrm{ml}$ min-I and were controlled by Waters M680 automated gradient controller. The sample was injected into the column by Waters $116 \mathrm{~K}$ injector. Peak of each pigment was detected at $445 \mathrm{~nm}$ by a Waters Lamba-Max M481 detector, and was further identified by standard method of Val et al [30].

\section{Results}

\section{Absorption spectra}

In comparison with that of green sector, the room temperature absorption spectra of acetone extracts of the white sector of mature variegated leaf showed a marked reduction of both chlorophylls and carotenoids (Figure 1).

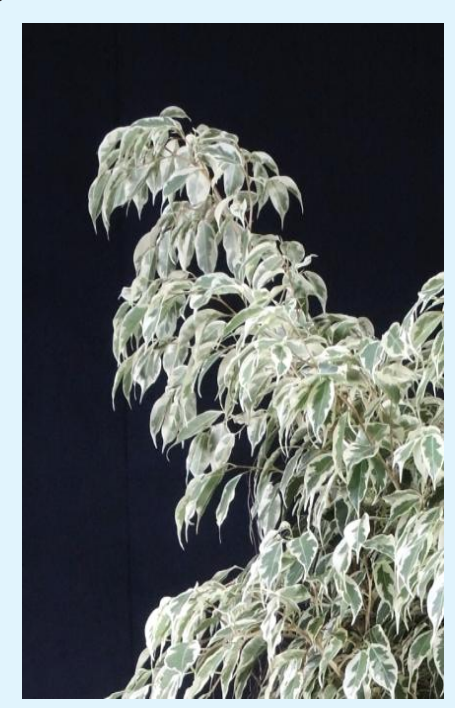

(A)

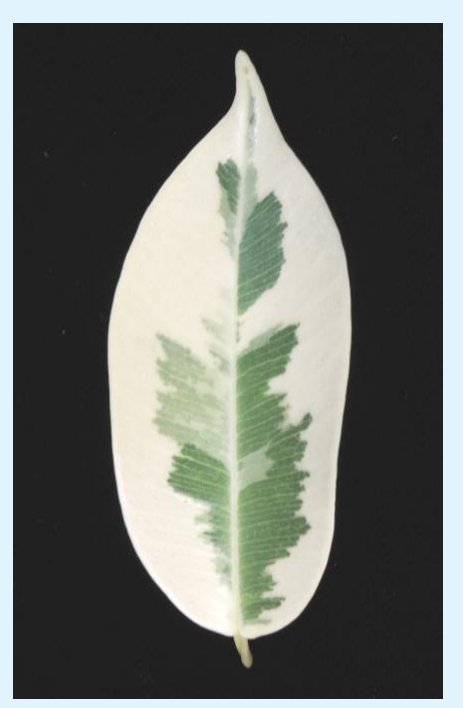

(B)
Huang MY and Yang CM, et al. Chlorophyll Biosynthetic Capacity and Xanthophyll Cycle of a White-Green Variegated Ficus microcarpa Cv. Milky Stripe. J Agri Res 2016, 1(3): 000117.

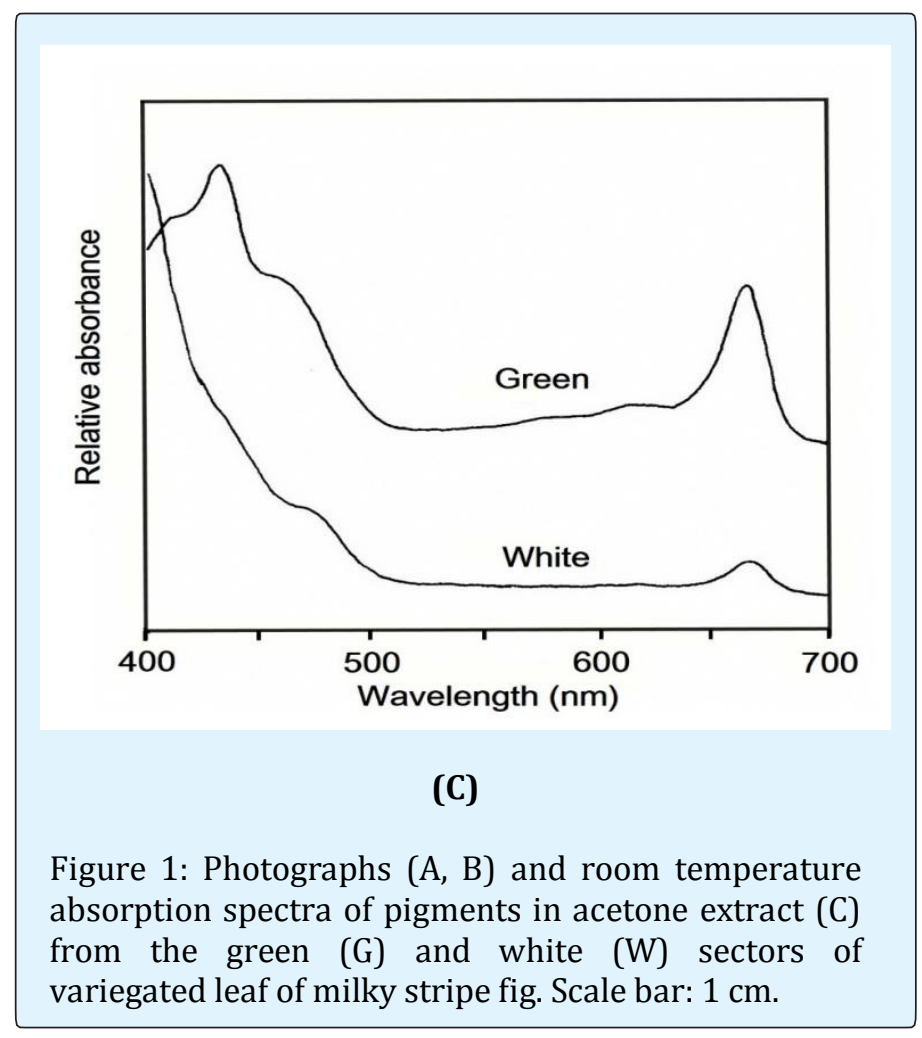

The white sector contains approximately $2.2 \%$ as much chlorophyll and approximately $9.5 \%$ as much carotenoids as does the green sector, but chlorophyll $\mathrm{a} / \mathrm{b}$ ratios were similar (Table 1).

\begin{tabular}{|c|c|c|c|c|}
\hline Tissue & $\begin{array}{c}\text { Chlorophyll } \\
\text { ( } \boldsymbol{\mu g} \text { g-1 leaf) }\end{array}$ & $\begin{array}{c}\mathbf{a} / \mathbf{b} \\
\text { ratio }\end{array}$ & $\begin{array}{c}\text { Carotenoid } \\
\text { ( } \mu \mathrm{g} \text { g-l leaf) }\end{array}$ & $\begin{array}{c}\text { Caroteno } \\
\text { id/chloro } \\
\text { phyll } \\
\text { ratio }\end{array}$ \\
\hline Green & $691 \pm 31(100)$ & $\begin{array}{l}2.56 \pm \\
0.18\end{array}$ & $190 \pm 11(100)$ & 1 \\
\hline White & $15 \pm 2(2.2)$ & $\begin{array}{l}2.47 \pm \\
0.21\end{array}$ & $18 \pm 2(9.5)$ & 5.3 \\
\hline
\end{tabular}

Table 1: Pigment content and chlorophyll a/b ratio in the green and white sectors of variegated leaf of milky stripe fig (percentage in parenthesis). The data are the mean of three determinations.

Ratio of carotenoids to chlorophyll in the white sector is 5.3 fold more than that in the green sector. 


\section{HPLC of carotenoids}

The chlorophyll and carotenoid in the green and white sectors of this plant used in this study were further examined with HPLC. The pigments were extracted and fractionated on a C18 reverse phase column (Figure 2 and Table 2).

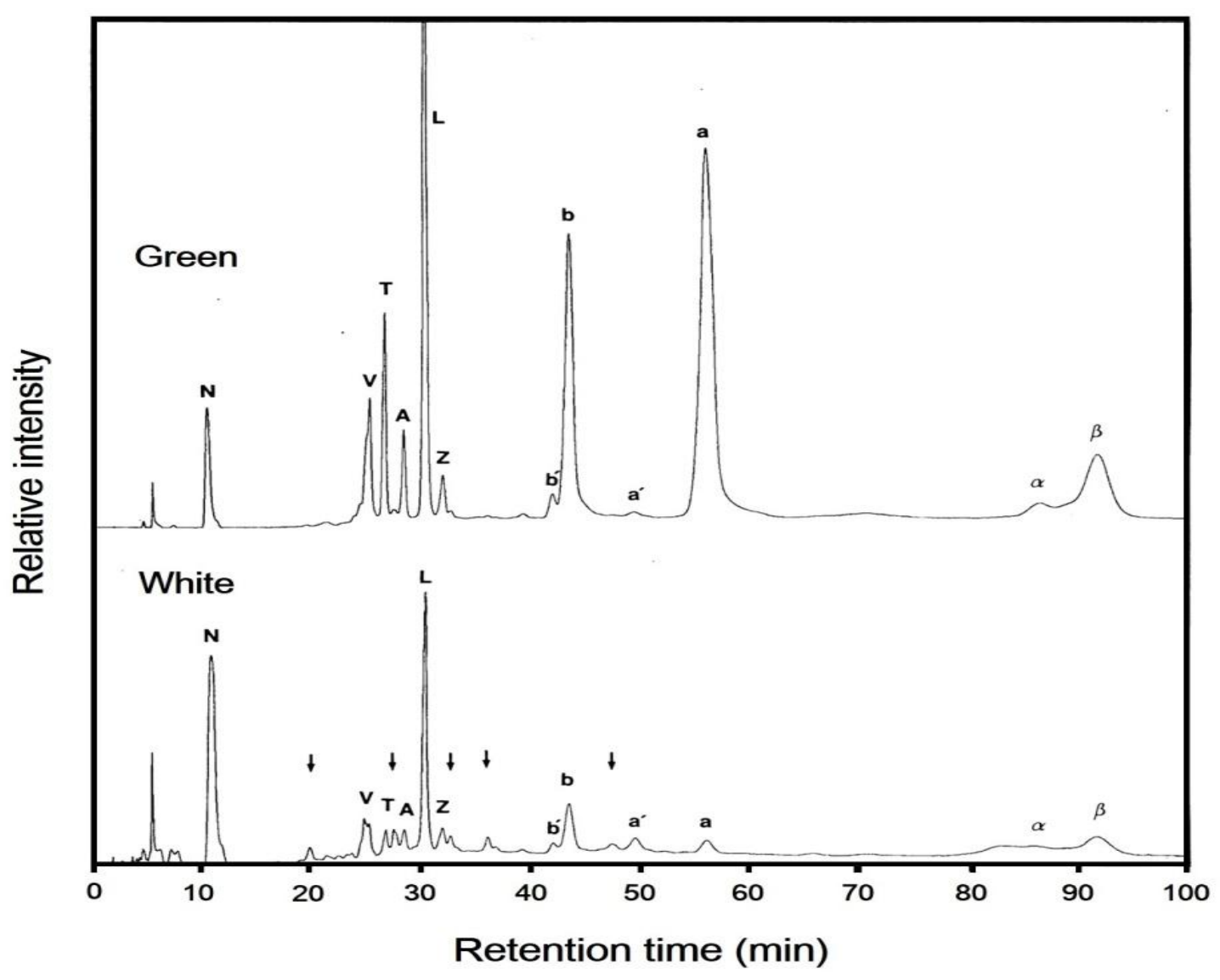

Figure 2: HPLC elution profiles of pigments from the green and white sectors of variegated leaf of milky stripe fig. Relative intensity refers to the absorbance at $445 \mathrm{~nm}$. Arrows show five unidentified peaks from the white part. The peaks were identified as follows: $\mathrm{N}$, neoxanthin; $\mathrm{V}$, violaxanthin; $\mathrm{T}$, taraxanthin; A, antheraxanthin; L, lutein; Z, zeaxanthin; b', pheophytin b, b, chlorophyll b; a', pheophytin a; a, chlorophyll a; $\alpha, \alpha$-carotene; $\beta$, $\beta$-carotene.

Twelve and seventeen peaks of material absorbing at $445 \mathrm{~nm}$ were eluted from the green and white sectors, respectively. These identities were ascribed on the basis of absorption spectra of the fractionated material (data not shown). Five unidentified peaks in the white sector were more abundant than in the green sector or were not present in the green sector (Figure 2). Both the green and white sectors contained $\alpha$-carotene $(2$ and $0.6 \%$ in total carotenoids, respectively). The relative amount of twelve identified pigments differed between green and white sectors (Table 2). 


\section{Open Access Journal of Agricultural Research}

\begin{tabular}{|c|c|c|c|c|}
\hline \multirow{2}{*}{ Pigments } & \multirow{2}{*}{$\begin{array}{l}\text { Retention } \\
\text { time (min) }\end{array}$} & \multicolumn{3}{|c|}{ Relative percent (\%) } \\
\hline & & Green & White & white/green \\
\hline Neoxanthin $(\mathrm{N})$ & 10.49 & $4.44 \pm 0.05(9.79)$ & $39.31 \pm 0.15(46.6)$ & $853(476)$ \\
\hline Violaxanthin (V) & 25.37 & $3.96 \pm 0.7(8.73)$ & $6.62 \pm 0.09(7.85)$ & $167(90)$ \\
\hline Taraxanthin $(\mathrm{T})$ & 26.72 & $4.47 \pm 0.4(9.85)$ & $0.66 \pm 0.05(0.78)$ & $17(8)$ \\
\hline Antheraxanthin (A) & 28.46 & $2.11 \pm 0.5(4.65)$ & $1.63 \pm 0.04(1.93)$ & $77(42)$ \\
\hline Lutein (L) & 30.37 & $18.37 \pm 0.12(40.5)$ & $25.28 \pm 0.12(30.0)$ & 138(74) \\
\hline Zeaxanthin (Z) & 31.99 & $1.06 \pm 0.03(2.34)$ & $1.11 \pm 0.1(1.32)$ & $105(56)$ \\
\hline Pheophytin b (b') & 42.08 & $0.44 \pm 0.02$ & $0.03 \pm 0.01$ & 7 \\
\hline Chlorophyll b (b) & 43.43 & $16.27 \pm 0.09$ & $8.76 \pm 0.02$ & 54 \\
\hline Pheophytin a (a') & 49.47 & $0.40 \pm 0.02$ & $3.27 \pm 0.01$ & 818 \\
\hline Chlorophyll a (a) & 56.06 & $37.52 \pm 0.21$ & $3.60 \pm 0.2$ & 10 \\
\hline$\alpha$-carotene $(\alpha)$ & 85.6 & $0.91 \pm 0.6(2.01)$ & $0.52 \pm 0.1(0.62)$ & $57(31)$ \\
\hline$\beta$-carotene $(\beta)$ & 91.74 & $10.7 \pm 0.11(22.2)$ & $9.10 \pm 0.2(10.8)$ & $9049)$ \\
\hline Total & & 100 & 100 & \\
\hline \multicolumn{2}{|c|}{ Carotenoid/chlorophyll } & 83 & 539 & 649 \\
\hline
\end{tabular}

Table 2: HPLC analyses of chlorophyll and carotenoid content in the green and white parts of variegated leaf of milky stripe fig grown in a greenhouse under natural illumination. Numbers in parentheses are the percentage of total carotenoids. The data are the mean of three determinations.

Excepting neoxanthin, all carotenoids were more abundant in the green sector than in the white sector. The quantity of taraxanthin in the white sector was only $8 \%$ of that in the green sector. While neoxanthin represents about half of the total carotenoids in the white sector, it represented less than $10 \%$ in the green sector. The ratio of carotenoid to chlorophyll calculated from HPLC data in the white sector was 6.5 fold more than that in the green sector, closing to the number (5.3) in Table 1.

\section{Porphyrin degradation and synthesis}

The degradation of PPIX, MGPP, and Pchlide in the green and white sectors of variegated leaf was also examined (Figure 3).

The relative degradation rates of the three intermediates in the green sector were slower than those in the white sector. The three intermediates in the green and white sectors of variegated leaf begin degradation after $2 \mathrm{~h}$ of incubation in darkness. In the green sector, MGPP and Pchlide degraded at similar rates, and at a slower rate than PPIX. This was in contrast to the three intermediates in the white sector. While in $20 \mathrm{~h}$, PPIX degraded 40\%, MGPP and Pchlide degraded more than $60 \%$, in the white sector.

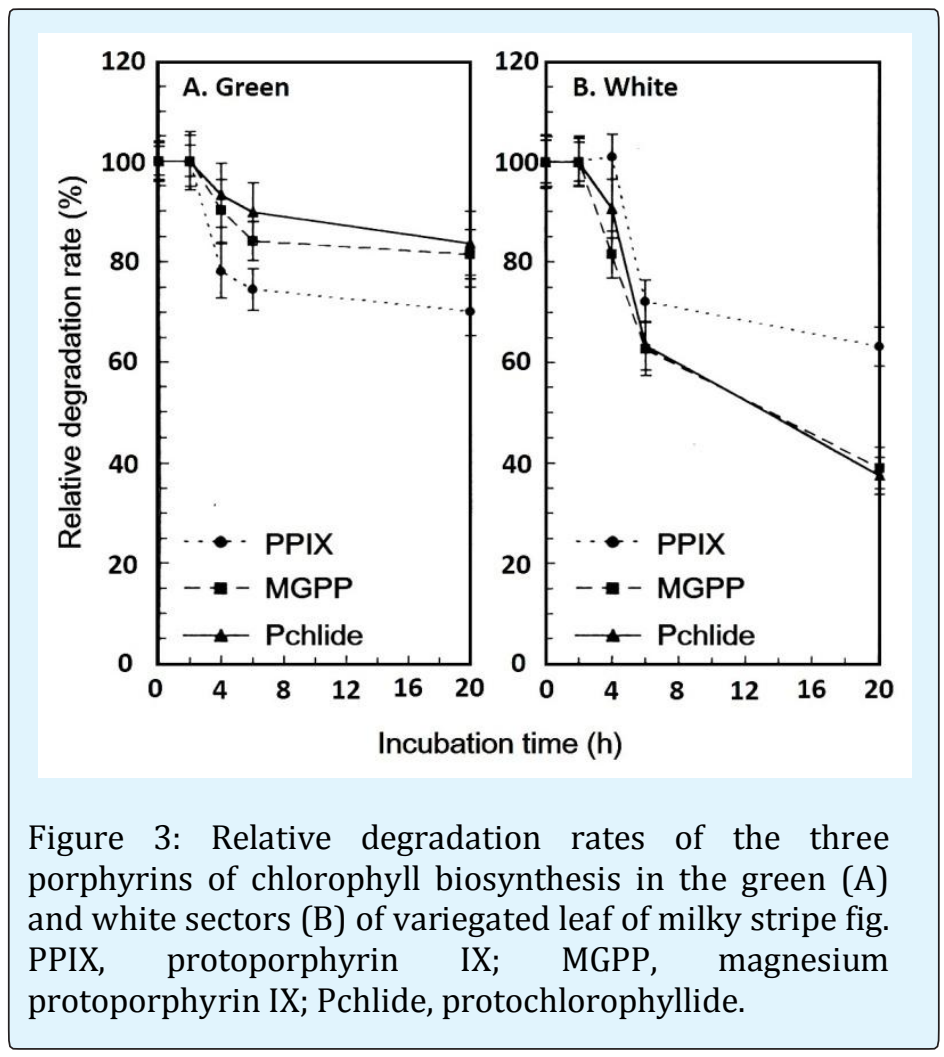

Huang MY and Yang CM, et al. Chlorophyll Biosynthetic Capacity and Xanthophyll Cycle of a White-Green Variegated Ficus microcarpa Cv. Milky 


\section{Open Access Journal of Agricultural Research}

In an attempt to ascertain whether the plants contain the requisite biosynthetic machinery for chlorophyll production, experiments measuring the production of Pchlide in detached leaf incubated in ALA were performed--usually with etiolated seedlings germinated and grown in the dark. Disks of punched leaf were incubated in the dark for $2,4,6$, and $20 \mathrm{~h}$ in solutions containing $2.5 \mathrm{mM}$ ALA. The leaves were then extracted and analyzed spectrophotometrically for the concentrations of three intermediates of chlorophyll biosynthesis (Table 3 ).

\begin{tabular}{|c|c|c|c|c|}
\hline \multicolumn{5}{|c|}{ A. Green part } \\
\hline \multicolumn{2}{|c|}{ Treatment } & PPIX & MGPP & Pchlide \\
\hline \multirow[t]{2}{*}{$2 \mathrm{~h}$} & control & $20.0 \pm 1.1(44.1)$ & $15.5 \pm 0.6(34.2)$ & $9.8 \pm 0.4(21.7)$ \\
\hline & $+\mathrm{ALA}$ & $19.9 \pm 1.2(42.6)$ & $16.1 \pm 0.4(34.4)$ & $10.8 \pm 0.5(23.0)$ \\
\hline \multirow[t]{2}{*}{$4 \mathrm{~h}$} & control & $32.7 \pm 2.1(45.5)$ & $24.3 \pm 0.6(33.8)$ & $14.9 \pm 0.6(20.7)$ \\
\hline & + ALA & $31.8 \pm 1.8(44.7)$ & $24.8 \pm 0.3(34.9)$ & $14.5 \pm 0.3(20.4)$ \\
\hline \multirow[t]{2}{*}{$6 \mathrm{~h}$} & control & $14.90 .9(40.6)$ & $13.0 \pm 0.4(35.5)$ & $8.8 \pm 0.4(24.0)$ \\
\hline & + ALA & $17.3 \pm 0.9(42.6)$ & $14.0 \pm 0.3(34.4)$ & $9.3 \pm 0.3(23.0)$ \\
\hline \multirow[t]{2}{*}{$20 \mathrm{~h}$} & control & $14.1 \pm 0.6(35.7)$ & $14.2 \pm 0.6(36.0)$ & $11.2 \pm 0.6(28.3)$ \\
\hline & $+\mathrm{ALA}$ & $22.9 \pm 1.3(40.3)$ & $19.2 \pm 0.8(33.9)$ & $14.6 \pm 0.4(25.8)$ \\
\hline \multicolumn{5}{|c|}{ B. White part } \\
\hline \multicolumn{2}{|c|}{ Treatment } & PPIX & MGPP & Pchlide \\
\hline \multirow[t]{2}{*}{$2 \mathrm{~h}$} & control & $9.2 \pm 0.6(45.7)$ & $7.1 \pm 0.4(35.4)$ & $3.8 \pm 0.3(19.0)$ \\
\hline & $+\mathrm{ALA}$ & $20.1 \pm 0.5(50.4)$ & $12.7 \pm 0.6(31.8)$ & $7.1 \pm 0.4(17.9)$ \\
\hline \multirow[t]{2}{*}{$4 \mathrm{~h}$} & control & $9.3 \pm 0.6(50.1)$ & $5.8 \pm 0.6(31.2)$ & $3.5 \pm 0.4(18.7)$ \\
\hline & + ALA & $14.0 \pm 0.4(48.9)$ & $9.4 \pm 0.6(32.7)$ & $5.3 \pm 0.3(18.4)$ \\
\hline \multirow[t]{2}{*}{$6 \mathrm{~h}$} & control & $6.7 \pm 0.4(49.1)$ & $4.5 \pm 0.4(33.0)$ & $2.4 \pm 0.2(17.9)$ \\
\hline & $+\mathrm{ALA}$ & $16.3 \pm 0.6(49.7)$ & $10.4 \pm 0.3(31.7)$ & $6.1 \pm 0.4(18.6)$ \\
\hline \multirow[t]{2}{*}{$20 \mathrm{~h}$} & control & $5.8 \pm 0.3(57.9)$ & $2.8 \pm 0.3(27.8)$ & $1.4 \pm 0.4(14.3)$ \\
\hline & + ALA & $11.2 \pm 0.4(49.8)$ & $6.3 \pm 0.4(28.2)$ & $5.0 \pm 0.3(22.0)$ \\
\hline
\end{tabular}

Table 3: Accumulation of PPIX, MGPP, and Pchlide in control and ALA-supplemented green and white parts of variegated leaf of milky stripe Fig. The unit for the three intermediates is nmol g-1 fresh leaf. Numbers in the parenthesis are the percentage of individual porphyrin relative to the sum of PPIX, MGPP, and Pchlide. The data are the mean of three determinations

As expected of $20 \mathrm{~h}$ incubation in the dark, the concentrations of PPIX, MGPP, and Pchlide increased in the green sector incubated in the presence of ALA relative to that in its absence. An increase of the three intermediates, however, did not took place at least during the first six hour of dark incubation in the presence of
ALA. As shown in Figure 4, not only did the concentrations of the three intermediates increased in the white sector in the presence of ALA over its absence, but also all increases happened in the $2 \mathrm{~h}$ period following ALA-supplementation (Figure 4). 


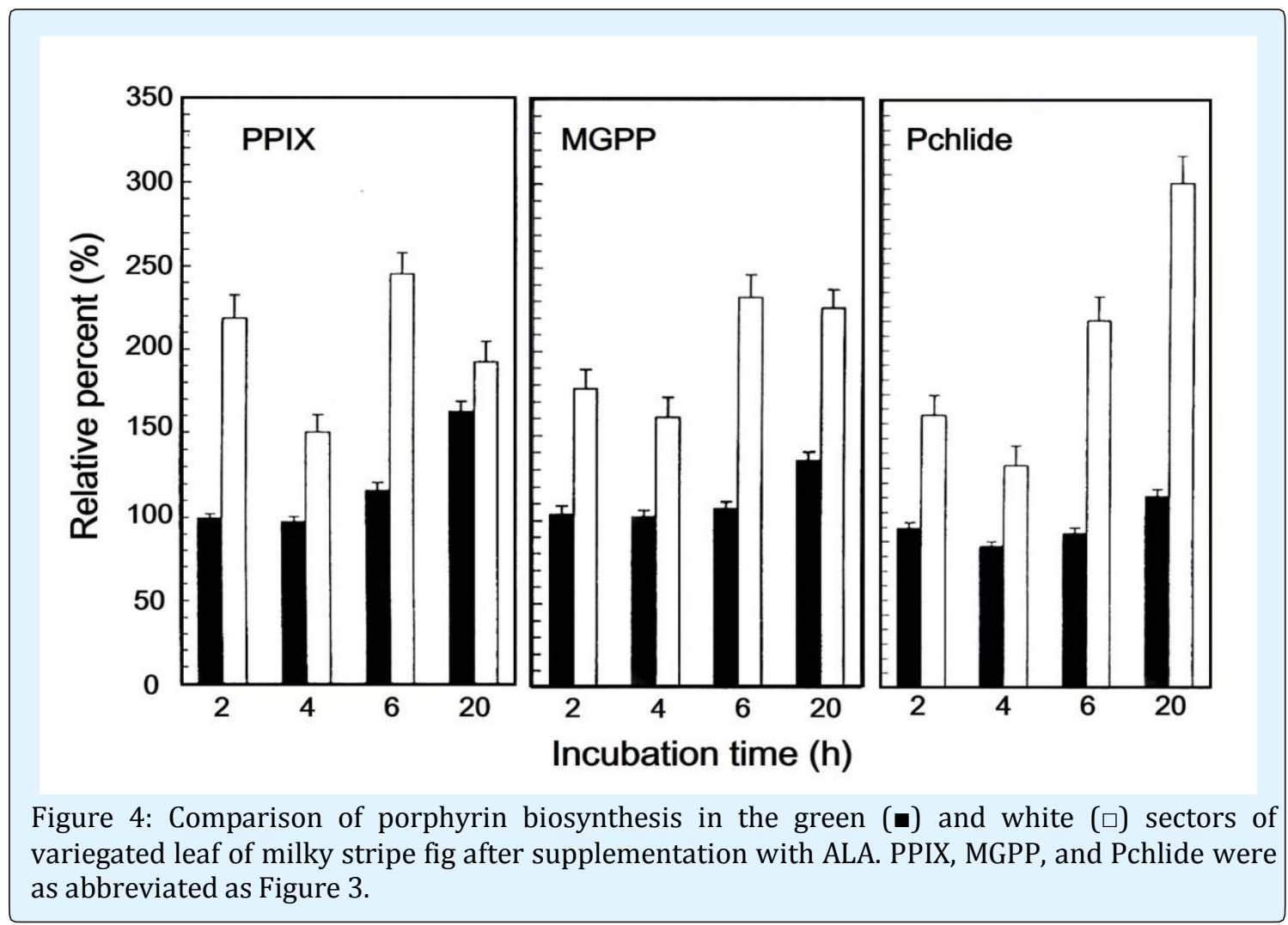

The quantities of the three intermediates in the white sector supplemented with exogenous ALA never reached that in the green sector with ALA. The relative percentage of PPIX to their sum in the green sector was approximately $10 \%$ higher than that in the white sector and that of Pchlide was $2 \sim 8 \%$ lower (Table 3 ).

\section{Xanthophyll Cycle}

The epoxidation index which indicates a displacement toward violaxanthin, is defined as 0.5 antheraxanthin \%
+ vialaxanthin \%) /100 [31]. Table 4 showed the epoxidation indices of the green and white sectors of variegated leaf of milky stripe fig grown in a greenhouse under mild natural illumination. The VAZ pool of the white sector was approximately $30 \%$ smaller than that of the green sector (green: 15.7\%; white: 11.1 in VAZ/carotenoid). On the other hand, the epoxidation index for the white sector was approximately $13 \%$ higher than that for the green sector (green: $70.3 \%$; white: $79.4 \%)$.

\begin{tabular}{|c|c|c|c|c|c|}
\hline \multirow{2}{*}{ Tissue } & \multicolumn{3}{|c|}{ VAZ pigments } & \multirow{2}{*}{ VAZ/carotenoids } & \multirow{2}{*}{ Epoxidation index } \\
\cline { 2 - 5 } & $\mathbf{V}$ & $\mathbf{A}$ & $\mathbf{Z}$ & & 0.71 \\
\hline Green & $0.56 \pm 0.02$ & $0.30 \pm 0.02$ & $0.15 \pm 0.01$ & 0.16 & 0.8 \\
\hline White & $0.71 \pm 0.03$ & $0.17 \pm 0.01$ & $0.12 \pm 0.01$ & 0.11 & 1.13 \\
\hline White/green & 1.27 & 0.57 & 0.8 & 0.69 & \\
\hline
\end{tabular}

Table 4: Amount of xanthophylls relative to total carotenoids, and epoxidation index for the green and white parts of variegated leafs of milky stripe fig. The data are the mean of three determinations. 


\section{Open Access Journal of Agricultural Research}

\section{Discussion}

In this report we examined the characteristics of three porphyrins and of xanthophyll cycle components in the green and white sectors of variegated leaf of milky stripe Fig. We showed that the white sector of variegated leaf contains little pigments and reduced absorbance (Figure 1 , Table 1). We also found that the chlorophyll a/b ratio is similar to that of the green sector. In the Arabidopsis im mutant, however, the chlorophyll $\mathrm{a} / \mathrm{b}$ ratio is enhanced in the green sector [10]. The authors suggest that the increased chlorophyll $\mathrm{a} / \mathrm{b}$ ratio is a protective adaption for im to avoid photooxidative damage [10]. Accordingly, the unchanged chlorophyll $\mathrm{a} / \mathrm{b}$ ratio in milky stripe fig might indicate that milky stripe has alternative photoprotective mechanism(s).

Present study showed that the level of carotenoid was declined as well as chlorophyll in the white sector (Table 1). In the previous report, it is found that the deficiency in carotenoids can result in decreased chlorophyll content [32]. Although the total contents of carotenoids were decreased in white sector, our observation that the higher carotenoid to chlorophyll ratio in the white sector than that in the green sector indicated a non-association between the deficiency in chlorophyll and the loss of carotenoids (Table 1; Figure 2). A similar results is described in a chlorophyll b-deficient mutant of sweet clover [33], showing an elevated ratio of lutein and carotene to chlorophyll. Carotenoids are considered to be able to protect plant from oxidative damage by multiple pathway $[34,17]$. The increased ratio of carotenoid to chlorophyll in white sector might be the adaptive mechanism for milky stripe fig to prevent or reduce the oxidative stress.

When comparing to green sector, the epoxidation index was elevated in the white sector, suggesting that under the same growth conditions the xanthophyll cycle operates faster in the white sector than in the green sector (Table 4). This further indicated that the white sector of variegated leaf adapted to the alteration of light intensity over a narrower range than does the green sector, and that the white sector was more sensitive to light. In our analysis of carotenoid contents, it was showed that the VAZ pool was smaller in white sector than that in green sector. This result was in contrast to the finding in Arabidopsis im mutant, which demonstrates a higher VAZ pool size is occurred in the white sector [35]. This inconsistency might accounts for the regulatory responses in the chlorophyll deficient sector are different either between different species or between natural adapted and mutant plant. In present study, we also observed a dramatically increased of neoxanthin percentage in white sector (Table 2). This observation indicated a greater biosynthetic activity was induced in milky stripe and might provide a possible explanation for the reduced percentage of VAZ/carotenoid in the white sector of the milky stripe fig (Table 4). This result provides the functional evidence that xanthophyll cycle is the photoprotective mechanism in the white sector of milky stripe.

A chlorophyll-deficient ch5 mutant of Arabidopsis operates its xanthophyll cycle at a lower capacity than does the wild type, and is more sensitive to the alteration of light intensity. It seems that the deficiency in the accumulation of chlorophyll also results in a deficiency in the capacity of the xanthophyll cycle to absorb excess light in response to the stress of intense illumination. It is also likely that a chlorophyll-deficient mutant containing relatively high ratio of carotenoid to chlorophyll may not require as great a xanthophyll cycle capacity as does the wild type [29]. In the present case, the white sector of variegated leaf of milky stripe fig is similar to the leaf of chlorophyll-deficient mutant (deficient in pigments and with a high ratio of carotenoid to chlorophyll) display similar behavior.

Another major finding in this report is that the metabolism of porphyrin/chlorophyll in the white sector was highly activated in the presence of ALA (Figure 4). Whereas the PPIX, MGPP, and Pchlide synthesis in green sector was increased after 20 hours of ALA exposure, the synthesis of these intermediates in white sector, to our surprise, was able to respond rapidly to ALA treatment within 2 hours (Figure 4, Table 3). In previous studies, the chlorophyll-deficient plants are characterized with biochemical defects including a great reduction of chlorophyll, abnormal chlorophyll a/b ratios, marked changes in chlorophyll-protein complexes, and an inability to photo reduce protochlorophyllide $[1,12]$. In present study, we found that the quantities of three intermediates were declined in white sector (Table 3). We also found a higher degradation rate of these intermediates in the white sector (Figure 3). According to the results of the reduced intermediates and the rapid response of ALA treatment in chlorophyll synthesis process, our data indicated that chlorophyll biosynthesis between ALA and Pchlide was partially impaired in the white sector of variegated leaf, but the chlorophyll biosynthesis was completely impaired in the steps after Pchlide. Our finding was consisted to the transcriptomic study of im in Arabidopsis, which demonstrates that the 


\section{Open Access Journal of Agricultural Research}

gene expressions of enzymes (PORB and PORC) involving in the conversion of Pchlide to Chlide are down-regulated in the white sector [36]. Despite the synthesis process, the degradation of chlorophyll might be another factor that affects the chlorophyll content in white sector. In our previous study, the activities of chlorophyllase $\mathrm{a}$ and $\mathrm{b}$ are significantly elevated in the white sector of milky stripe, suggesting another possible mechanism was induced for reducing chlorophyll in the white sector [37]. Whether or why these enzymes are involved in regulating the variegation of the milky stripe fig is still need further investigation.

The variegation patterns of milky stripe can be majorly classified as three. In addition to the common pattern descripted in introduction, several variegated leaves in milky stripe are showed to be a common pattern at left (or right) side of leaf blade and the whole white at another side of leaf blade across the midrib. The other pattern is a whole white leaf without green sector (data not shown). The chlorophyll formation of Ficus microcarpa cv. Golden-leaves is light or/and temperaturesensitive $[38,39]$, and therefore the yellowing of leaf in Golden-leaves is found to be induced by high light exposure [40]. In milky stripe, however, distinct patterns are found in the leaves exposed to the same environmental (light and temperature) condition. Much remains unknown about the mechanisms behind the determination of the variegation patterns. Recently, a study reveals the association IAA and the IAA responsive gene EaF82a in the variegation of Epipremnum aureum [41]. Their results suggested a new direction for studying the regulatory pathway of plant variegation by looking into the function of IAA. Moreover, whether other plant hormones are involved in the formation of variegation is worth for studying.

\section{Acknowledgements}

This research was supported by a grant (NSC99-2311B-034-01-MY2) from the Ministry of Science and Technology, Taiwan, Republic of China.

\section{References}

1. Evenari M (1989) The history of research on whitegreen variegated plants. Botanical Review 55(2): 106139.

2. Yu F, Fu A, Aluru M, Park S, Xu Y, et al. (2007) Variegation mutants and mechanisms of chloroplast biogenesis. Plant, Plant Cell Environ 30(3): 350-365.
3. Fornasiero RB, Bianchi A, Manenti G, Manzini ML (1981) Plastid ultrastructure in variegated varieties of some ornamental shrubs. Caryologia 34(3): 317326.

4. Grandi GT, Severi A, Menenti G (1981) Plastidial ultrastructure in variegated plants of Weigela florida DC. Caryologia 34(3): 289-296.

5. Manenti G (1975) The structure of variegated leaves of Acer negundo L. A light and electron microscope study. Israel Journal of Botany 24: 61-70.

6. Sun CN (1966) Ultrastructure of plastids in normal and variegated leaves in Abutilon striatum. Cytologia 31: 452-456.

7. Tanno JA, Webster TR (1982) Variegation in Selaginella martensii f. albovariegata. ll. Plastid structure in mature leaves. Canadian Journal of Botany 60(11): 2383-2384.

8. Valanne N, Valanne T (1972) Structure of plastids of a variegated Betula pubescens mutant. Canadian Journal of Botany 50(9): 1835-1839.

9. Webster TR, Tanno JA (1980) Inheritance of pigment deficiencies and ultrastructural defects in plastids of Selaginella Kraussiana var. aurea. Canadian Journal of Botany 58(17): 1929-1937.

10. Aluru MR, Bae H, Wu D, Rodermel SR (2001) The Arabidopsis immutans mutation affects plastid differentiation and the morphogenesis of white and green sectors in variegated plants. Plant Physiol 127(1): 67-77.

11. Chen M, Jensen M, Rodermel S (1999) The yellow variegated mutant of Arabidopsis is plastid autonomous and delayed in chloroplast biogenesis. J Hered 90(1): 207-214.

12. Yang CM, Hsu JC, Chen YR (1993) Light- and temperature-sensitivity of chlorophyll-deficient and virescent mutants. Taiwania 38(3,4): 49-56.

13. Fabel TG, Staehelin LA (1996) Partial block in the early steps of the chlorophyll synthesis pathway: a common feature of chlorophyll b-deficient mutants. Plant Physiology 97(2): 311-320.

14. Peltier G, Cournac L (2002) Chlororespiration. Annual Review of Plant Biology 53: 523-550. 


\section{Open Access Journal of Agricultural Research}

15. Wetzel CM, Jiang CZ, Meehan LJ, Voytas DF, Rodermel SR (1994) Nuclear-organelle interactions: the immutans variegation mutant of Arabidopsis is plastid autonomous and impaired in carotenoid biosynthesis. Plant J 6(2): 161-175.

16. Lindahl M, Spetea C, Hundal T, Oppenheim AB, Adam $\mathrm{Z}$, (2000) The thylakoid FtsH protease plays a role in the light-induced turnover of the photosystem II D1 protein. Plant Cell 12(3): 419-431.

17. Demmig-Adams B (1990) Carotenoids and photoprotection in plants: a role for the xanthophyll zeaxanthin. Biochimica et Biophysica Acta 1020(1): 124.

18. Demmig-Adams B, Adams III WW (1992) Photoprotection and other responses of plants to high light stress. Annual Review of Plant Physiology and Plant Molecular Biology 43: 599-626.

19. Demmig-Adams B, Adams WW (1993) The xanthophyll cycle. In: Young A, Britton M (Eds.), Carotenoids in photosynthesis. Chapman and Hall, London pp 206-251.

20. Horton P, Ruban AV, Walters RG (1996) Regulation of Light Harvesting in Green Plants. Annual Review of Plant Physiology and Plant Molecular Biology 47: 655-684.

21. Bilger W, Bjorkman O (1990) Role of the xanthophyll cycle in photoprotection elucidated by measurements of light-induced absorbance changes, fluorescence and photosynthesis in leaves of Hedera canariensis. Photosynthesis Research 25(3): 173-185.

22. Demmig-Adams B, Winter K, Kruger A, Czygan FC (1989) Light response of $\mathrm{CO}_{2}$ assimilation, dissipation of excess excitation energy, and zeaxanthin content of sun and shade leaves. Plant Physiology 90(3): 881-6.

23. Gilmore AM (2000) Mechanistic role of xanthophylldependent photoprotection in higher plant chloroplasts and leaves. Physiologia Plantarum 99(1): 197-209.

24. Ivanov AG, Sane P, Hurry V, Kro IM, Sveshnikov D, et al. (2003) Low-temperature modulation of the redox properties of the acceptor side of photosystem II: photoprotection through reaction centre quenching of excess energy. Physiologia Plantarum 119(3): 376383.
25. Murchie EH, Pinto M, Horton P (2009) Agriculture and the new challenges for photosynthesis research. New Phytologist 181(3): 532-552.

26. Yang CM, Chang KW, Yin MH, Huang HM (1998) Methods for the determination of the chlorophylls and their derivatives. Taiwania 43(2): 116-122.

27. Braumann T, Grimme LH (1981) Reversed-phase high performance liquid chromatography of chlorophylls and carotenoids. Biochimica et Biophysica Acta 367(1): 8-17.

28. Lu YK, Yang CM (1995a) Characterization of the thylakoid membrane in a chlorophyll-deficient ch5 mutant of Arabidopsis thaliana. Botanical Bulletin Academia Sinica 36: 32-40.

29. Lu YK, Yang CM, Hsu JC, Chen YR (1995b) Response of the xanthophyll cycle to changes in low irradiance in a chlorophyll-deficient ch5 mutant of Arabidopsis thaliana. Photosynthetica 31(4): 541-547.

30. Val J, Abadia J, Heras L, Monge E (1986) Higher plant photosynthetic pigments analysis: determination of carotenoids and chlorophylls by HPLC. Journal of Micronutrient Analysis 2: 305-312.

31. Morales F, Abadia A, Abadia J (1990) Characterization of the xanthophyll cycle and other photosynthetic pigment changes induced by iron deficiency in sugar beet (Beta vulgaris L.). Plant Physiology 94(2): 607613.

32. Mayfield SP, Taylor WC (1984) Carotenoid-deficient maize seedlings fail to accumulate light-harvesting chlorophyll a/b binding protein (LHCP) mRNA. Eur J Biochem 144(1): 79-84.

33. Markwell JP, Danko SJ, Bauwe H, Osterman J, Gorz HJ, et al. (1986) A temperature-sensitive chlorophyll bdeficient mutant of sweetclover (Melilotus alba). Plant Physiol 81(2): 329-334.

34. Dall'Osto L, Bassi R, Ruban AV (2014) Photoprotective Mechanisms: Carotenoids. In: Theg SM., Wollman FA (Eds.), Plastid Biology. Springer Dordrecht Heidelberg London New York, USA.

35. Baerr JN, Thomas JD, Taylor BG, Rodermel SR, Gray GR, (2005) Differential photosynthetic compensatory mechanisms exist in the immutans mutant of Arabidopsis thaliana. Physiologia Plantarum 124(3): 
390-402.

36. Aluru MR, Zola J, Foudree A, Rodermel SR (2009) Chloroplast photooxidation-induced transcriptome reprogramming in Arabidopsis immutans white leaf sectors. Plant Physiology 150(2): 904-923.

37. Chen MCM, Chao PY, Huang MY, Yang JH, Yang ZW, et al. (2012) Chlorophyllase activity in green and nongreen tissues of variegated plants. South African Journal of Botany 81: 44-49.

38. Chen HY, Yang CM (1995) Temperature-sensitivity of chlorophyll expression in the leaves of Ficus microcarpa cv. Golden-Leaf Figure Proceedings of the National Science Council, Republic of China. Part B, Life sciences 19: 196-200.
39. Yang CM, Hsu JC, Chen YR (1995) Light-sensitivity of chlorophyll formation in the leaves of Ficus microcarpa cv. Golden-leaves. Bot Bull Acad Sin 36: 215-221.

40. Yamasaki H, Heshiki R, Ikehara N (1995) mLeafgoldenning induced by high light in Ficus microcarpa L. f., a Tropical Figure Journal of Plant Research 108(2): 171-180.

41. Hung CY, Umstead ML, Chen J, Holliday BM, Kittur FS, et al. (2014) Differential expression of a novel gene EaF82a in green and yellow sectors of variegated Epipremnum aureum leaves is related to uneven distribution of auxin. Physiologia Plantarum 152(4): 749-762 